\title{
Call for Nominations for the MRS Von Hippel Award
}

The Awards Committee of the MRS, chaired this year by Past President Woody White, announces that nominations are being accepted for the Society's highest award, the Arthur von Hippel Award of the Materials Research Society. By virtue of its conception and the outstanding scientists who number among it's recipients, this award has become an international hallmark of excellence in the field of materials research.

The Award is named for the Emeritus Professor of the Massachusetts Institute of Technology whose laboratory pioneered the collaborative, interdisciplinary research that subsequently has taken the identity of "materials science." It recognizes those qualities most prized by materials scientists brilliance and originality of intellect, combined with vision that transcends conventional scientific disciplines. The award is presented annually by the Society at its Fall Meeting.
Past recipients of the Award are:

Prof. Arthur von Hippel

Dr. William O. Baker

Prof. David Turnbull

Prof. W. Conyers Herring

Prof. James W. Mayer

Prof. Clarence M. Zener

Prof. Sir Peter B. Hirsch

Dr. Walter L. Brown

"While the award is perhaps better defined by the list of past recipients than by any statement of philosophy, the scientists who have received it certainly do embody those qualities that the award was designed to honor," Committee Chair White points out.

The recipient is selected by majority vote of the MRS Council from a slate of candidates that is prepared by the Awards Committee. Any member of the MRS can make nominations to the Committee. Names put into nomination are, in accordance with MRS by-laws, considered active for three years.
"Because the number of nominations is expected to be quite large," reports White, "the committee will accept only those that are submitted on the summary form that is included in this issue of the BULLETIN."

The summary form is important, according to White, "Because reproduction, mailing, and consideration of lengthy documentation on each candidate is prohibitive, given the number of candidates that we expect to be nominated this year. Our initial screening of candidates will be based upon the information contained on the summary form."

Nominations covered by the completed summary, should be sent to:

C. W. White, MRS Past President Solid State Division

Oak Ridge National Laboratory Oak Ridge, TN 37831

\section{NOMINATION DEADLINE:} July 1, 1985

Additional copies of the Von Hippel Award Nomination Summary Form may be obtained from MRS Headquarters

\section{North Carolina Section Holds Plasma Processing Workshop}

The North Carolina Section of MRS recently sponsored a highly successful workshop on Plasma Processing, hosted by the Microelectronics Center of North Carolina. Carlton Osburn, program chairperson for the workshop held January 9, 1985, indicated that over 70 participants attended the day-long event featuring several invited speakers from around the country.

Linda Ephrath of IBM-Fishkill, who spoke on Reactive Ion Etching, and Tom Mayer of the University of North Carolina, who led the discussion session on Etching, rounded out the morning portion of the program. After lunch, Dennis Hess of the University of California at Berkeley spoke on Plasma Deposition; Gerry Lucovsky, North Carolina State University at Raleigh, discussed Remote Plasma Enhanced CVD of $\mathrm{SiO}_{2}$ and $\mathrm{Si}_{3} \mathrm{~N}_{4}$, and Arnie Reisman, Microelectronics Center of North Carolina, spoke about Plasma Oxidation. The program concluded with a presentation on Electron and Ion Beam Interactions with Organic Resists by Rich Linton of the University of North Carolina at Chapel Hill.

Plans are underway for upcoming topical programs through the Section, and Section Treasurer J. Narayan and Secretary M. Paesler report that membership in the local group is now at 102 . For additional information on the activities of the North Carolina Section, contact Section President Wei-Kan Chu, Department of Physics and Astronomy, University of North Carolina, Phillips Hall 039 A, Chapel Hill, NC 27514; telephone (919) 962-3014.

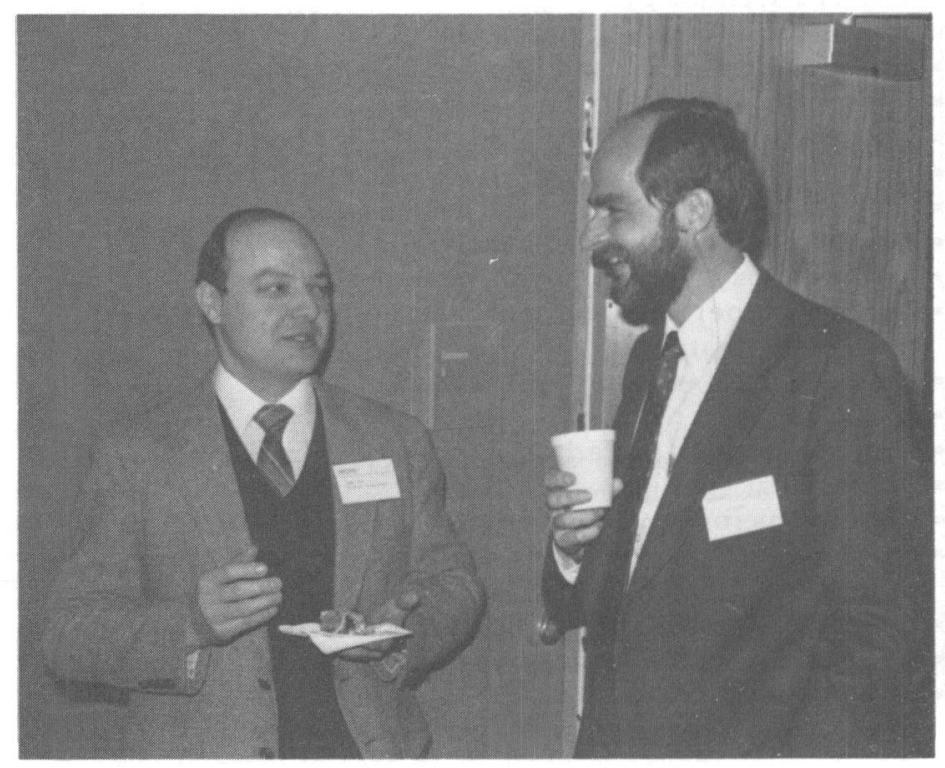

Dennis Hess (left) and Program Chairperson Carlton Osburn take a break between sessions of Plasma Processing Workshop. 